\title{
Oral health conditions and frailty in Mexican community-dwelling elderly: a cross sectional analysis
}

Roberto Carlos Castrejón-Pérez ${ }^{1,3+}$, S Aída Borges-Yáñez ${ }^{2^{*}{ }^{+}}$, Luis M Gutiérrez-Robledo ${ }^{3}$ and J Alberto Ávila-Funes ${ }^{4}$

\begin{abstract}
Background: Oral health is an important component of general well-being for the elderly. Oral health-related problems include loss of teeth, nonfunctional removable dental prostheses, lesions of the oral mucosa, periodontitis, and root caries. They affect food selection, speaking ability, mastication, social relations, and quality of life. Frailty is a geriatric syndrome that confers vulnerability to negative health-related outcomes. The association between oral health and frailty has not been explored thoroughly. This study sought to identify associations between the presence of some oral health conditions, and frailty status among Mexican community-dwelling elderly.

Methods: Analysis of baseline data of the Mexican Study of Nutritional and Psychosocial Markers of Frailty, a cohort study carried out in a representative sample of people aged 70 and older residing in one district of Mexico City. Frailty was defined as the presence of three or more of the following five components: weight loss, exhaustion, slowness, weakness, and low physical activity. Oral health variables included self-perception of oral health compared with others of the same age; utilization of dental services during the last year, number of teeth, dental condition (edentate, partially edentate, or completely dentate), utilization and functionality of removable partial or complete dentures, severe periodontitis, self-reported chewing problems and xerostomia. Covariates included were gender, age, years of education, cognitive performance, smoking status, recent falls, hospitalization, number of drugs, and comorbidity. The association between frailty and dental variables was determined performing a multivariate logistic regression analysis. Final models were adjusted by socio-demographic and health factors

Results: Of the 838 participants examined, 699 had the information needed to establish the criteria for diagnosis of frailty. Those who had a higher probability of being frail included women $(O R=1.9)$, those who reported myocardial infarction $(O R=3.8)$, urinary incontinence $(O R=2.7)$, those who rated their oral health worse than others $(\mathrm{OR}=3.2)$, and those who did not use dental services $(\mathrm{OR}=2.1)$. For each additional year of age and each additional drug consumed, the probability of being frail increased $10 \%$ and $30 \%$, respectively.
\end{abstract}

Conclusions: Utilization of dental services and self-perception of oral health were associated with a higher probability of being frail.

Keywords: Elderly, Oral health, Frailty syndrome, Utilization of dental services

\footnotetext{
* Correspondence: aborges@unam.mx

${ }^{\dagger}$ Equal contributors

${ }^{2}$ Coordinación de Salud Pública Bucal, División de Estudios de Posgrado e

Investigación, Facultad de Odontología, Universidad Nacional Autónoma de

México, Ciudad Universitaria, Av. Universidad 3000, Del. Coyoacán, C.P.

04510Distrito Federal, México

Full list of author information is available at the end of the article
} 


\section{Background}

The mouth and its associated structures participate actively in protective and biological functions, and are essential for social activities [1-3]. The aging people experience a wide variety of oral health problems, such as loss of teeth, edentulism, periodontitis, coronal and root caries, oral mucosal lesions, utilization of nonfunctional dental prostheses (either partial or complete), xerostomia, and chewing problems, among others [4-8]. These problems begin earlier in life and can promote a decline in general health because reduced nutrient intake, pain, and low quality of life [4,9-16].

Dental problems in the elderly are associated with modifications in food selection, changes in nutrient intake $[6,7,10,13,17,18]$, chronic conditions such as diabetes [19], and with cardiovascular problems [20-22]. Oral health problems can be considered chronic diseases because their prevalence and duration; besides, risk factors are common with those of other chronic diseases, such as diabetes or cardiovascular problems [2,6,13,23-25].

Frailty syndrome is characterized by decreased resilience and physiological reserves, and is generally associated with an increased risk for disability, dependence, falls, hospitalization, and death [26-29]. Frailty results from excessive demands imposed on a system with a diminished capacity [30,31]; its prevalence ranges from $3-30 \%$ in people $\geq 65$ years old $[26,30,32,33]$.
To explain the approaches relating oral health status and the use of dental services with frailty; it is possible to build a four elements model. The first element is related to therapeutic decisions and the use of dental services, the second is focused on the functional ability of the mouth, the third one refers to the psychosocial process of the subject, and the fourth will focus on the cellular and physiological phenomena related with the inflammatory response. These components emerge from the deterioration of oral health due to either caries or periodontal disease, which can lead to the need for dental care [1-4], which may be used or not by the subjects leading to different outcomes affecting functionality and quality of life. Moreover, the first and fourth elements could also participate in both ways, periodontal inflammatory processes contribute to an increase in the levels of local and systemic inflammatory mediators and the increment of inflammation due to metabolic alterations contributes to the development or increased severity of periodontal disease, on the other hand, the reduction of mobility and development of disability or dependence consequence of frailty will affect the utilization of dental services because of problems of accessibility; this situation could contribute to the continuous deterioration of oral health (Figure 1).

It has been reported that the use of complete dentures and reports of chewing problems and loss of teeth are

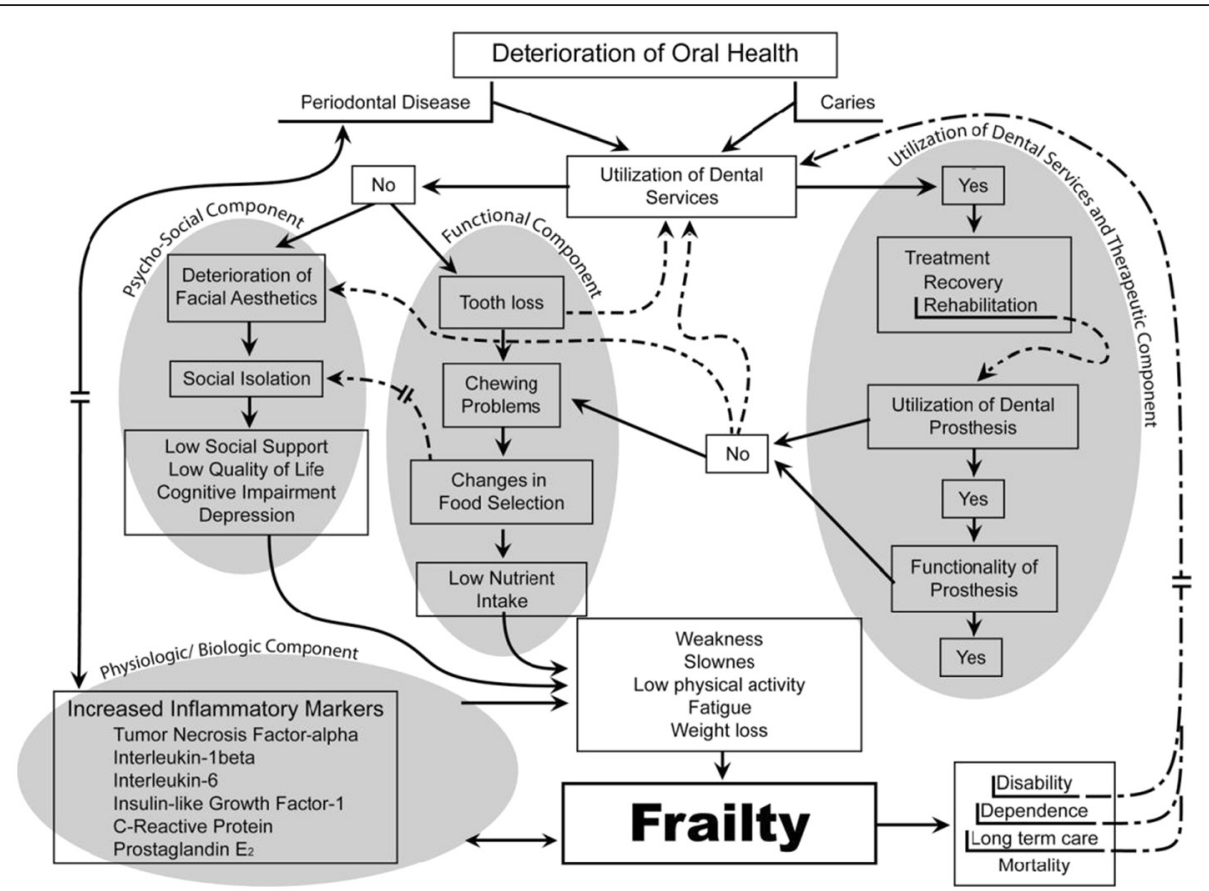

Figure 1 Proposed model for oral health and frailty. 
associated with fatigue (a component of frailty) and mortality in the elderly [34,35]. However, associations between other oral health conditions and frailty have not been explored.

The aim of our baseline data analysis was to determine the association between frailty and the presence of oral health conditions such as edentulism, number of teeth present, utilization and/or functionality of removable partial dentures (RPD) or complete dentures (CD), severe periodontitis, xerostomia, self-reported chewing problems, self-perception of oral health, and utilization of dental services during the previous year. The results were adjusted by gender, age, years of education, smoking status, history of myocardial infarction, previous stroke, hypertension, diabetes, osteoporosis, arthritis, urinary incontinence, falls, hospitalization, and number of drugs.

We tested the hypothesis that poor oral health conditions are associated with an increased probability of frailty in community-dwelling elderly.

\section{Methods}

The study sample is a subset of the participants of the Mexican Study of Nutritional and Psychosocial Markers of Frailty (the Coyoacan cohort), a prospective cohort study aiming to evaluate the nutritional and psychosocial determinants of frailty among Mexican communitydwelling elderly, conducted by the Department of Geriatrics of the National Institute of Medical Sciences and Nutrition "Salvador Zubirán" (INCMNSZ) of Mexico in collaboration with the National Institute of Public Health (INSP), the Department of Dental Public Health, the Graduate Studies and Research Division of the Dental School at the National Autonomous University of Mexico (UNAM), the Department of Health of the Government of the Federal District of Mexico, and the National Institute of Geriatrics of the Mexican Ministry of Health.

\section{Population}

The study population consisted of 33347 persons who lived independently in the District of Coyoacán, one of the 16 districts of Mexico City. They all received support from the Food Support, Medical Care, and Free Drugs Program, a local government program that serves $95 \%$ of elderly aged 70 and older. This district was selected because it was easily accessible and was home to citizens from a wide range of socioeconomic strata.

The sample was chosen by a random sampling procedure, stratified by age and gender, and we ensured a sample size that could reliably estimate a prevalence rate of frailty of at least $14 \%$ among participants with $\alpha=5 \%$ and $\beta=20 \%(n=1294)$.
Baseline data were collected during 2008 and 2009 in two stages. During the first stage, an interview was conducted using a standard questionnaire; during the second stage, a clinical (medical and dental) evaluation was carried out. The interview and clinical evaluation were carried out in the participant's home. The study protocol was approved by the Ethical Committee of the INCMNSZ. Each participant signed an informed consent and was free to refuse a specific part of the examination.

\section{Variables}

Frailty was defined according to the construct derived from the Cardiovascular Health Study [26] and validated in other studies [32,36]. Frail persons were identified as having three or more of the five following components: unintentional weight loss, poor endurance and energy, low physical activity, slowness, and weakness. These components were defined as follows:

$>$ Weight loss: self-reported weight loss of $5 \mathrm{~kg}$ or more in the last 6 months was considered positive for this item.

$>$ Poor endurance and energy: Self-report of exhaustion was assessed by two questions from the Center for Epidemiologic Studies-Depression scale (CES-D) [37]: "I felt that everything I did was an effort" and "I could not get going". Participants were asked: "How often, in the last week, did you feel this way?" and the answer was quoted as follows: $0=$ rarely or none of the time; 1 = some or a little of the time; 2 = a moderate amount of the time; or $3=$ most of the time.

Participants answering "2" (a moderate amount of the time) or " 3 " (most of the time) to either of these two questions were considered as frail for this criterion. > Low physical activity: The Physical Activity Scale for the Elderly questionnaire (PASE) [38] was used to assess physical activity. Participants who scored in the lowest quintile adjusted for gender were categorized as frail for the low physical activity criterion.

> Slowness: A response "yes" or "can't do" to any of the following questions was used to estimate slowness: Because of a health problem, "do you have difficulty walking one block?" or "do you have difficulty with climbing several flights of stairs without resting?" > Weakness: participants who answered "yes" to the question Because of a health problem, "do you have difficulty with lifting or carrying objects weighting over 5 $\mathrm{kg}$, like a heavy bag of groceries?" were categorized as frail for this criterion.

\section{Oral health variables}

Number of teeth. (0-32 teeth): Number of natural teeth present in the mouth. 
Dental condition (edentulism/partial edentulism/completely dentate): Edentulism is defined as the absence of all natural teeth; partial edentulism is defined as having one to 24 natural teeth; completely dentate is defined as having $\geq 25$ teeth [39].

Utilization of removable partial dentures (RPD) or complete dentures (CD) (Yes/No): Determined during the clinical examination. Participants were asked to show their RPD or CD to the examiner; both those who were using dentures at the time of the evaluation and those who showed but did not use them were classified as denture users.

Functionality of Removable Partial Dentures or Complete Dentures (Functional/Nonfunctional): Evaluation of the stability, retention, occlusion, extension, and integrity of the dental prosthesis, as proposed by Ettinger [40]. Dentures failing in one or more of the above criteria were considered nonfunctional. Prostheses were also considered nonfunctional when the subjects expressed that they did not wear their removable prostheses regularly.

Severe periodontitis (Yes/No): Periodontitis status was evaluated using a modified version of the Periodontal Screening and Recording Index (PSR) [41]; we measured the clinical attachment loss of periodontal ligament by probing six sites per tooth (distobuccal, midbuccal, mesiobuccal, mesiolingual, midlingual, and distolingual) on all teeth present in the mouth, recording the highest PSR score on each tooth. We classified each participant according to the following criteria: Severe periodontitis was defined as having at least one tooth with a PSR score of 3 (3.5-5.5 mm of attachment loss) and furcation involvement or gingival recession of $\geq 3.5 \mathrm{~mm}$, or at least one tooth with a PSR score of 4 ( $>5.5 \mathrm{~mm}$ of attachment loss); the absence of severe periodontitis was defined by all teeth having PSR scores of 0 thru $3(0-5.5 \mathrm{~mm}$ of attachment loss) without furcation involvement or gingival recession.

The following variables were assessed during the interview: self-perception of oral health compared with other persons of the same age (Better/Equal/Worse), utilization of dental services during the last year (Yes/No), xerostomia (Yes/No), and self-reported chewing problems (Yes/ No).

\section{Covariates}

The following socio-demographic and health variables were collected by interview: age, gender, education level (years), current and past smoking (Yes/No); cognitive impairment as evaluated by the Mini-Mental State Examination (MMSE) ( $\leq 18 / 19-30)$ [42]; urinary incontinence (Yes/No); falls three times or more in the previous 12 months (Yes/No); hospitalization in the previous
12 months (Yes/No), and the number of medications per day.

The presence or absence of six self-reported diseases was interrogated for their relationship with dental conditions and frailty: myocardial infarction, stroke, hypertension, diabetes, osteoporosis, and arthritis.

\section{Interview}

The interview was completed by $86.9 \%$ of the study sample $(\mathrm{n}=1124) ; 24$ persons could not be reached, 37 refused to participate, 18 were deceased, and the remaining 91 did not participate for other reasons. The interviews were performed by trained and standardized interviewers (Figure 2).

\section{Clinical evaluation}

The participants were visited by an interdisciplinary team, consisting of a physician, a nutritionist, and a dentist. The subjects underwent a comprehensive geriatric health evaluation including examination of functional status, pharmacological treatments, physical performance, nutritional status and oral condition.

The oral evaluation included determination of the number of teeth present in the mouth, dental condition, use and functionality of RPD and CD, and presence of severe periodontitis. The dentists who carried out this evaluation were students of the dental school at UNAM; they were previously standardized in periodontal evaluation (Kappa $=0.7$ ) and evaluation of the functionality of RPD and CD (Kappa =0.9). The clinical evaluation was performed with artificial light, a dental mirror (\#5), and

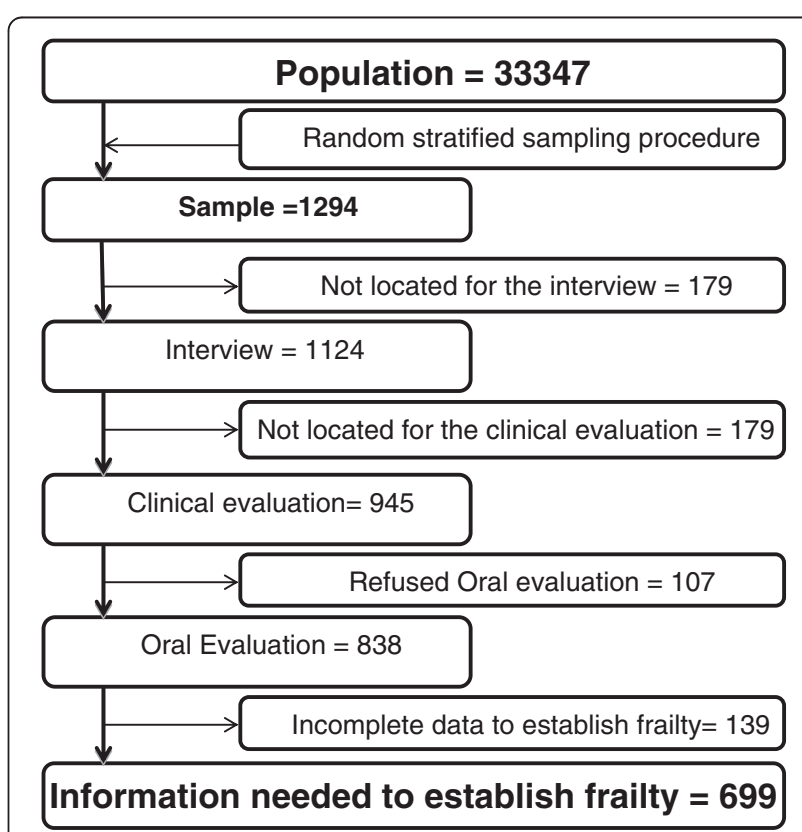

Figure 2 Flowchart. Flow of participants. 
a periodontal probe $\left(\mathrm{CP} 11.5 \mathrm{~B}, \mathrm{Hu}-\right.$ Friedy $\left.^{\circledR}\right)$, which had been previously sterilized; infection control procedures were strictly followed.

The overall clinical evaluation was completed by 945 subjects, and 107 subjects refused the oral evaluation; $74.5 \%(838 / 1124)$ of participants completed both the interview and the oral clinical evaluation (Figure 2).

\section{Analysis}

Variables were described using frequencies and proportions or arithmetic means and standard deviations (SD) when appropriate. Univariate analyses testing oral health conditions (and covariates) with frailty status were carried out using chi-squared test for categorical data (selfrated oral health compared with others, xerostomia, dental condition, periodontitis, and utilization and functionality of RPD and/or CD), estimating the odds ratio when appropriate. Student's $\mathrm{t}$ test for independent groups were also performed.

A binary logistic regression model was used, employing frailty status as the dependent variable and the dental variables (perception of oral health compared with others, utilization of dental services during the previous year, xerostomia, report of chewing problems, number of teeth, and severe periodontitis) as independent variables. We also included interactions between history of smoking and severe periodontitis, diabetes and hospitalization, diabetes and hypertension, diabetes and severe periodontitis, diabetes and number of teeth present, myocardial infarction and hypertension, myocardial infarction and hospitalization, and hypertension and hospitalization. Utilization and functionality of RPD and $\mathrm{CD}$ were excluded because of their collinearity with the number of teeth. Socio-demographic and medical covariables identified as statistically significant in the univariate analysis were also included. The final model was determined by performing a backward variable selection procedure.

A p-value of 0.05 was used as the threshold for statistical significance, and 95\% confidence intervals (95\% CI) were estimated when appropriate. SPSS software for Windows (SPSS Inc., Chicago, IL, version 19) was used to perform all statistical tests.

\section{Results}

The overall mean age was $77.9 \pm 6.3$ years; $53.2 \%$ $(\mathrm{n}=372)$ were women; $67.6 \%(\mathrm{n}=221)$ of men were married, and $51.3 \%(n=191)$ of women were widowed; men had completed more years of schooling (mean = $7.9 \pm 5.8)$ than women $($ mean $=6.7 \pm 5.0 ; \mathrm{p}<0.01$ ).

The prevalence of frailty was $15.0 \%(\mathrm{n}=105)$, with $12.2 \%(n=40)$ prevalence among men and $17.5 \%(n=65)$ prevalence among women.
The mean number of teeth present was $10.7 \pm 9.2$, with a $23.5 \%(n=197)$ prevalence of edentulism; $9.1 \%$ of the participants $(n=76)$ had $\geq 25$ teeth. The utilization of RPD and/or CD among edentate or partially dentate subjects was $61.9 \%(n=472)$; of these, $67.6 \%(n=319)$ of RPDs and CDs were not functional. The prevalence of severe periodontitis was $8.9 \%(n=57)$ among subjects who were partially or completely dentate (Table 1 ).

Among all subjects, 23.8\% suffered from cognitive impairment; $19 \%$ suffered from urinary incontinence; $8.4 \%$ had suffered $\geq 3$ falls in the previous year; $49.8 \%$ reported former or current smoking; $11.1 \%$ were hospitalized during the previous year; $8.4 \%$ had suffered myocardial infarction; $3.9 \%$ had suffered a stroke; $55.3 \%$ had hypertension; $21.5 \%$ were diabetics; $13.6 \%$ reported having osteoporosis; $15.6 \%$ had arthritis; and the mean number of drugs taken daily was $2.75 \pm 2.2$.

No significant differences were found in the prevalence of frailty based on number of falls in the previous year $(\mathrm{p}=0.11)$, smoking status $(\mathrm{p}=0.35)$, hypertension $(\mathrm{p}=0.10)$, diabetes $(\mathrm{p}=0.80)$, severe periodontitis $(\mathrm{p}=0.29)$, utilization of removable or complete dentures $(\mathrm{p}=0.19)$, or functionality of partial or complete dentures $(\mathrm{p}=0.37)$ (Table 2$)$.

The analysis also showed that frail participants were older (mean $=81.6 \pm 6.6, \mathrm{p}<0.001$ ), and that participants were more likely to be frail if they scored $\leq 18$ on the MMSE (OR $=2.6$; 95\% CI 1.5-4.2), reported urinary incontinence $(\mathrm{OR}=3.5 ; 95 \% \mathrm{CI} 2.2-5.6)$, were hospitalized during the last year $(\mathrm{OR}=3.2 ; 95 \% \mathrm{CI} 1.8-5.4)$, had a history of myocardial infarction $(\mathrm{OR}=2.1 ; 95 \%$ CI $1.1-$ 3.9), had suffered a stroke (OR $=3.7 ; 95 \%$ CI 1.5-9.1), suffered from osteoporosis ( $\mathrm{OR}=2.6$; 95\% CI 1.5-4.3), suffered from arthritis $(\mathrm{OR}=2.0 ; 95 \%$ CI 1.2-3.3), did not use dental services the previous year $(\mathrm{OR}=1.7 ; 95 \%$ CI 1.1-2.5), reported xerostomia $(\mathrm{OR}=1.6$; $95 \%$ CI 1.0 $2.4)$, or reported chewing problems $(\mathrm{OR}=2.0 ; 95 \% \mathrm{CI}$ 1.3-3.0). Further, frail subjects used a higher number of drugs on a daily basis (mean $=4.1 \pm 2.8, \mathrm{p}<0.001)$ and had a lower mean number of teeth (mean $=8.3 \pm 8.6$, $\mathrm{p}<0.001$ ) than non-frail subjects. The prevalence of frailty was higher among those who perceived that their oral health was worse than others of the same age (25\%) $(\mathrm{p}=0.006)$ and among edentulous subjects $(23.5 \%)$ $(\mathrm{p}=0.003)$. (Table 2$)$

\section{Logistic regression model}

The bivariate logistic regression model included gender, age, cognitive performance (MMSE), incontinence, hospitalization during the last year, history of myocardial infarction, stroke, osteoporosis, arthritis, number of drugs taken daily, self-perception of oral health, utilization of dental services during the last year, xerostomia, self-report of chewing problems, number of teeth present, and severe periodontitis. 
Table 1 Prevalence of oral health conditions among elderly $\geq 70$ years old from Mexico City, 2009

\begin{tabular}{|c|c|c|}
\hline \multicolumn{2}{|l|}{ Oral health Conditions } & \multirow{2}{*}{$\frac{\mathbf{n}(\%)}{314(37.5)}$} \\
\hline Self-perception of oral health compared with others of the same age & Better & \\
\hline & Equal & $289(34.5)$ \\
\hline & Worse & $82(9.8)$ \\
\hline & Don't Know, & $153(18.2)$ \\
\hline & Not Answered & \\
\hline & Total & 838 \\
\hline \multirow[t]{4}{*}{ Utilization of dental services during the last year } & Yes & $387(46.2)$ \\
\hline & No & $450(53.7)$ \\
\hline & Not answered & $1(0.1)$ \\
\hline & Total & 837 \\
\hline \multirow[t]{4}{*}{ Chewing problems } & No & $444(53.0)$ \\
\hline & Yes & $393(46.9)$ \\
\hline & Not answered & $1(0.1)$ \\
\hline & Total & 838 \\
\hline \multirow[t]{4}{*}{ Xerostomia } & No & $458(54.7)$ \\
\hline & Yes & $378(45.1)$ \\
\hline & Not answered & $2(0.2)$ \\
\hline & Total & 838 \\
\hline \multirow[t]{4}{*}{ Number of teeth } & Mean (SD) & $10.7(9.2)$ \\
\hline & Median & 10 \\
\hline & Maximum & 32 \\
\hline & Total & 838 \\
\hline \multirow[t]{4}{*}{ Dental condition } & Edentulism & $197(23.5)$ \\
\hline & Partial edentulism & $565(67.4)$ \\
\hline & Dentate $\geq 25$ teeth & $76(9.1)$ \\
\hline & Total & 838 \\
\hline \multirow[t]{3}{*}{ Utilization of RPD and/or CD among edentate and partially dentate } & Not wearing & $290(38.1)$ \\
\hline & Wearing RPD and/or CD & $472(61.9)$ \\
\hline & Total & 762 \\
\hline \multirow[t]{3}{*}{ Functionality of RPD and/or CD among RPD and CD users } & Non functional & $319(67.6)$ \\
\hline & Functional & $153(32.4)$ \\
\hline & Total & 472 \\
\hline \multirow[t]{4}{*}{ Periodontitis among partially and complete dentate } & Not severe & $580(91.1)$ \\
\hline & Severe & $57(8.9)$ \\
\hline & Rejected evaluation & 4 \\
\hline & Total & 641 \\
\hline
\end{tabular}

$\mathrm{RPD}=$ Removable Partial Denture; $\mathrm{CD}=$ Complete Denture

The final model adequately describes the data (Hosmer-Lemeshow goodness-of-fit $=0.101$ ), explains $34.4 \%$ (Nagelkerke pseudo r-squared) of the variability in frailty classification, and properly classifies $88.2 \%$ of the participants.

The final model showed an increased probability of frailty among women $(\mathrm{OR}=1.9 ; 95 \% \mathrm{CI} 1.07-3.5)$, those who reported urinary incontinence $(\mathrm{OR}=2.7 ; 95 \% \mathrm{CI}$
1.5-4.9), those who had suffered myocardial infarction $(\mathrm{OR}=3.8$; 95\% CI 1.004-14.1), those who reported their oral health to be worse than others of the same age $(\mathrm{OR}=3.2 ; 95 \% \mathrm{CI} 1.4-7.2)$, and those who did not use dental services during the previous year $(\mathrm{OR}=2.1 ; 95 \%$ CI 1.2-3.7); also, for each additional year of age and each additional drug consumed per day, the probability of being frail increased $10 \%$ and $30 \%$, respectively. Frailty 
Table 2 Sociodemographic, medical and oral health characteristics by frailty status, elderly $\geq 70$ years from Mexico City, 2009

\begin{tabular}{|c|c|c|c|c|c|c|c|}
\hline \multirow[t]{2}{*}{ Variable } & \multirow[t]{2}{*}{ Scale } & \multicolumn{3}{|l|}{ Frailty (\%) } & \multirow[t]{2}{*}{$p$} & \multirow[t]{2}{*}{ OR } & \multirow[t]{2}{*}{$95 \% \mathrm{Cl}$} \\
\hline & & No & Yes & Total & & & \\
\hline \multirow[t]{2}{*}{ Age } & Mean (SD) & $77.2(5.9)$ & $81.6(6.6)$ & $77.9(6.3)$ & $<0.001$ & & \\
\hline & Total & 594 & 105 & 699 & & & \\
\hline \multirow[t]{3}{*}{ Sex } & Male & $287(87.8)$ & $40(12.2)$ & 327 & 0.053 & 1.52 & $0.99-2.33$ \\
\hline & Female & $307(82.5)$ & $65(17.5)$ & 372 & & & \\
\hline & Total & $594(85.0)$ & $105(15.0)$ & 699 & & & \\
\hline \multirow[t]{3}{*}{ MMSE } & $19-30$ & $523(87)$ & $78(13.0)$ & 601 & $<0.001$ & 2.55 & $1.54-4.22$ \\
\hline & $\leq 18$ & $71(72.4)$ & $27(27.6)$ & 98 & & & \\
\hline & Total & $594(85.0)$ & $105(15.0)$ & 699 & & & \\
\hline \multirow[t]{3}{*}{ Urinary incontinence } & No & 507 (88.9) & $63(11.1)$ & 570 & $<0.001$ & 3.49 & $2.18-5.59$ \\
\hline & Yes & $83(69.7)$ & $36(30.3)$ & 119 & & & \\
\hline & Total & 590 & 99 & 689 & & & \\
\hline \multirow[t]{3}{*}{$\geq 3$ falls during the previous 12 months } & No & $502(85.8)$ & $83(14.2)$ & 585 & 0.11 & 1.71 & $0.88-3.30$ \\
\hline & Yes & $46(78.0)$ & $13(22.0)$ & 59 & & & \\
\hline & Total & 548 & 96 & 644 & & & \\
\hline \multirow[t]{3}{*}{ Smoking } & No & $282(83.7)$ & $55(16.3)$ & 337 & 0.35 & 0.82 & $0.52-1.25$ \\
\hline & Yes & $312(86.2)$ & $50(13.8)$ & 362 & & & \\
\hline & Total & 594 & 105 & 699 & & & \\
\hline \multirow[t]{3}{*}{ Hospitalization previous 12 months } & No & $543(87.0)$ & $81(13.0)$ & 624 & $<0.001$ & 3.15 & $1.84-5.41$ \\
\hline & Yes & $51(68.0)$ & $24(32.0)$ & 75 & & & \\
\hline & Total & 594 & 105 & 699 & & & \\
\hline \multirow[t]{3}{*}{ Myocardial infarction } & No & $549(85.9)$ & $90(14.1)$ & 639 & 0.02 & 2.08 & $1.11-3.89$ \\
\hline & Yes & $44(74.6)$ & $15(25.4)$ & 59 & & & \\
\hline & Total & 593 & 105 & 698 & & & \\
\hline \multirow[t]{3}{*}{ Stroke } & No & $580(85.7)$ & $97(14.3)$ & 677 & 0.003 & 3.68 & $1.49-9.11$ \\
\hline & Yes & $13(61.9)$ & $8(38.1)$ & 21 & & & \\
\hline & Total & 593 & 105 & 698 & & & \\
\hline \multirow[t]{3}{*}{ Hypertension } & No & $254(84.9)$ & $45(15.1)$ & 299 & 1.00 & 1.00 & $0.66-1.52$ \\
\hline & Yes & 333 (84.9) & $59(15.1)$ & 392 & & & \\
\hline & Total & 587 & 104 & 691 & & & \\
\hline \multirow[t]{3}{*}{ Diabetes } & No & $466(84.9)$ & $83(15.1)$ & 549 & 0.80 & .936 & $0.56-1.57$ \\
\hline & Yes & $126(85.7)$ & $21(14.3)$ & 147 & & & \\
\hline & Total & 592 & 104 & 696 & & & \\
\hline \multirow[t]{3}{*}{ Osteoporosis } & No & $518(87.2)$ & 76 (12.8) & 594 & $<0.001$ & 2.57 & $1.54-4.28$ \\
\hline & Yes & 69 (72.6) & $26(27.4)$ & 95 & & & \\
\hline & Total & 587 & 102 & 689 & & & \\
\hline \multirow[t]{3}{*}{ Arthritis } & No & 510 (86.6) & 79 (13.4) & 589 & 0.005 & 2.02 & $1.23-3.34$ \\
\hline & Yes & $83(76.1)$ & $26(23.9)$ & 109 & & & \\
\hline & Total & 593 & 105 & 698 & & & \\
\hline \multirow[t]{3}{*}{ Utilization of dental services previous 12 months } & Yes & $302(88.3)$ & $40(11.7)$ & 342 & 0.020 & 1.65 & $1.08-2.54$ \\
\hline & No & $292(82.0)$ & $64(18.0)$ & 356 & & & \\
\hline & Total & 594 & 104 & 698 & & & \\
\hline
\end{tabular}


Table 2 Sociodemographic, medical and oral health characteristics by frailty status, elderly $\geq 70$ years from Mexico City, 2009 (Continued)

\begin{tabular}{|c|c|c|c|c|c|c|c|}
\hline \multirow[t]{3}{*}{ Xerostomia } & No & $342(87.5)$ & $49(12.5)$ & 391 & 0.038 & 1.55 & $1.02-2.35$ \\
\hline & Yes & $252(81.8)$ & $56(18.2)$ & 308 & & & \\
\hline & Total & 594 & 105 & 699 & & & \\
\hline \multirow[t]{3}{*}{ Chewing problems } & No & $343(88.9)$ & $43(11.1)$ & 386 & 0.001 & 1.97 & $1.29-3.00$ \\
\hline & Yes & $251(80.2)$ & $62(19.8)$ & 313 & & & \\
\hline & Total & 594 & 105 & 699 & & & \\
\hline \multirow[t]{3}{*}{ Severe periodontitis } & No & $443(87.7)$ & $62(12.3)$ & 505 & 0.29 & 1.54 & $0.69-3.47$ \\
\hline & Yes & $37(82.2)$ & $8(17.8)$ & 45 & & & \\
\hline & Total & 480 & 70 & 550 & & & \\
\hline \multirow[t]{3}{*}{ Utilization of RPD or CD } & No & $185(81.9)$ & $41(18.1)$ & 226 & 0.19 & 0.75 & $0.48-1.16$ \\
\hline & Yes & $349(85.7)$ & $58(14.3)$ & 407 & & & \\
\hline & Total & 534 & 99 & 633 & & & \\
\hline \multirow[t]{3}{*}{ Functionality of RPD or CD } & Yes & $117(88.0)$ & $16(12.0)$ & 133 & 0.37 & 1.32 & $0.71-2.45$ \\
\hline & No & $232(84.7)$ & $42(15.3)$ & 274 & & & \\
\hline & Total & 349 & 58 & 407 & & & \\
\hline \multirow[t]{2}{*}{ Number of medications used daily } & Mean (SD) & $2.6(1.9)$ & $4.1(2.8)$ & $2.8(2.2)$ & $<0.001$ & & \\
\hline & Total & 585 & 104 & 689 & & & \\
\hline \multirow[t]{3}{*}{ Number of teeth present } & Mean (SD) & $11.8(9.2)$ & $8.3(8.6)$ & $11.3(9.2)$ & $<0.001$ & & \\
\hline & Median & 11 & 6 & 10 & & & \\
\hline & Total & 594 & 105 & 699 & & & \\
\hline \multirow[t]{4}{*}{ Self-perception of oral health compared with others } & Better & $275(89.0)$ & $34(11.0)$ & 309 & 0.006 & & \\
\hline & Same & $237(83.5)$ & $47(16.5)$ & 284 & & & \\
\hline & Worse & $57(75.0)$ & $19(25.0)$ & 76 & & & \\
\hline & Total & 569 & 100 & 669 & & & \\
\hline \multirow[t]{4}{*}{ Dental condition } & Complete Edentulism & $114(76.5)$ & $35(23.5)$ & 149 & 0.003 & & \\
\hline & Partial Edentulism & $420(86.8)$ & $64(13.2)$ & 484 & & & \\
\hline & Dentate & $60(90.9)$ & $6(9.1)$ & 66 & & & \\
\hline & Total & 594 & 105 & 699 & & & \\
\hline
\end{tabular}

MMSE = Minimental State Examination; RPD = Removable Partial Denture; $C D=$ Complete Denture.

prevalence was not significantly different based on hospitalization during the previous year $(\mathrm{OR}=2.4 ; 95 \%$ CI $0.99-5.7, \mathrm{p}=0.053)$ or based on severe periodontitis $(\mathrm{OR}=3.8 ; 95 \%$ CI 0.93-15.4, $\mathrm{p}=0.062)$ (Table 3$)$.

\section{Discussion}

We observed, using a representative sample of people $\geq 70$ years old who resided in one district of Mexico City, that the perception of having worse oral health than others of the same age and the failure to utilize dental services were associated with an increased probability of being frail. This is the first study that has explored frailty in the Mexican elderly and included oral health components. The multidisciplinary approach of this project allows us to explore the relationships between frailty and many other variables [32].
There are few previous data on the association between oral health and some components of the frailty syndrome, but not with the frailty syndrome overall [34,35].

There was an association between not using dental services during the past year and a higher probability of being frail and $(\mathrm{OR}=2.1,95 \% \mathrm{CI} 1.2-3.8)$; Overall, the utilization of dental services among the elderly is lower [43] (49\% in this study) than the utilization of medical services (85\%) [44]. According to Kiyak [45], elderly people who believe that declining health is a part of aging and that recovery is not possible, reflect that attitude by not utilizing dental services. Taking this into account, the observed lack of utilization of dental services might also reflect compromised general health, which in turn may be correlated with frailty. 
Table 3 Final logistic regression model for frailty, elderly $\geq 70$ years old from Mexico City, 2009

\begin{tabular}{|c|c|c|c|c|c|c|}
\hline & \multirow[t]{2}{*}{ Wald } & \multirow[t]{2}{*}{ DF } & \multirow[t]{2}{*}{$\mathbf{P}$} & \multirow[t]{2}{*}{ OR } & \multicolumn{2}{|c|}{$95 \% \mathrm{Cl}$} \\
\hline & & & & & Lower & Upper \\
\hline Sex (Women) & 4.72 & 1 & 0.03 & 1.94 & 1.07 & 3.52 \\
\hline Age (years) & 17.62 & 1 & 0.00 & 1.09 & 1.05 & 1.14 \\
\hline MMSE ( $\leq 18)$ & 2.50 & 1 & 0.11 & 1.72 & 0.88 & 3.39 \\
\hline Incontinence (yes) & 10.66 & 1 & 0.001 & 2.72 & 1.49 & 4.95 \\
\hline Hospitalization (yes) & 3.75 & 1 & 0.053 & 2.37 & 0.99 & 5.67 \\
\hline Medications per day (number) & 20.09 & 1 & 0.00 & 1.31 & 1.16 & 1.47 \\
\hline Myocardial infarction(yes) & 3.86 & 1 & 0.049 & 3.76 & 1.004 & 14.07 \\
\hline Stroke (yes) & 1.29 & 1 & 0.26 & 2.14 & 0.57 & 7.98 \\
\hline Osteoporosis (yes) & 2.55 & 1 & 0.11 & 1.76 & 0.88 & 3.51 \\
\hline \multicolumn{7}{|l|}{ Self-perception of oral health } \\
\hline Better & 8.63 & 2 & 0.01 & & & \\
\hline Same & 3.36 & 1 & 0.07 & 1.76 & 0.96 & 3.24 \\
\hline Worse & 8.23 & 1 & 0.004 & 3.23 & 1.45 & 7.21 \\
\hline Utilization of dental services (no) & 6.60 & 1 & 0.01 & 2.10 & 1.19 & 3.71 \\
\hline Number of teeth (number) & 0.65 & 1 & 0.42 & 0.99 & 0.95 & 1.02 \\
\hline Severe periodontitis (yes) & 3.48 & 1 & 0.062 & 3.79 & 0.93 & 15.37 \\
\hline Periodontitis * smoking & 0.63 & 1 & 0.43 & 0.43 & 0.05 & 3.51 \\
\hline Number of teeth * diabetes & 3.01 & 1 & 0.08 & 0.94 & 0.87 & 1.01 \\
\hline Stroke * hypertension & 0.63 & 1 & 0.43 & 0.52 & 0.10 & 2.59 \\
\hline Stroke ${ }^{*}$ hospitalization & 1.16 & 1 & 0.28 & 0.32 & 0.04 & 2.57 \\
\hline Diabetes * hospitalization & 0.47 & 1 & 0.49 & 1.76 & 0.35 & 8.78 \\
\hline Constant & 34.18 & 1 & 0.000 & 0.00 & & \\
\hline
\end{tabular}

MMSE = Minimental State Examination.

Another possible explanation could be constriction of life space, which has been recognized as a risk factor for frailty [46]. Constriction of life space is attributable to loss of mobility, weakness, and slowness, which result in difficulties with moving and travelling independently to receive dental care. This, in addition to low expectations about oral health, could contribute to this population's failure to utilize dental services.

The probability of being frail was 2.2 times higher for those who considered their oral health worse than others of the same age; this could be explained by the positive association between oral health and general health $[3,6]$. We can assume that a bad perception of oral health reflects declining general health.

Oral health is recognized as a component of general health [3], and it is unusual for people to identify oral health conditions as their only health problems when those issues are so advanced that they affect feeding ability, speaking, chewing, physical appearance, and social life, frequently producing pain and favoring depression [47-50]. Also, when oral health is poor, inflammation markers are increased, which in turn can alter the metabolism of other organs; even though self-perception of oral health is subjective, it can represent a risk indicator for frailty.

Oral health expectations among the elderly could also be influenced by age, education level, socioeconomic situation, and social support [51], variables that have been associated with frailty.

Even though the presence of severe periodontitis did not surpass the threshold of statistical significance as a predictor of frailty ( $\mathrm{OR}=3.9,95 \% \mathrm{CI} 0.98-15.6)$ in the final logistic model, the physiological process related to the development of periodontal infection could be related to the development of frailty. It has been shown that severe periodontitis is linked to energy imbalance, which in the elderly has been associated with loss of mobility and strength alterations that end with the development of frailty syndrome. It has been shown that higher concentrations of pro-inflammatory cytokines could favor the altered inflammation state observed in frailty syndrome $[29,52,53]$. It is important to point out that periodontitis requires the presence of teeth; in the logistic regression model, we included edentulous subjects in 
the "no severe periodontitis" group in order to preserve the sample size, but in a later analysis considering only completely or partially dentate (1-32 teeth) subjects, we observed that those with severe periodontitis have 5.3 times the risk for frailty than those without severe periodontitis (95\% CI 1.3-22.2). The participation of severe periodontitis in the development of frailty should be explored in the longitudinal analysis.

Other studies have explored the relationship between dental variables and frailty: Avlund et al. [34] reported that having few teeth increases the risk of fatigue in the elderly; also, Semba et al. [35] reported that frail edentate women with complete dentures who complain about chewing problems have higher mortality rates than frail edentulous women who reported no chewing problems. In this study, we did not find an association between the number of teeth and frailty or between chewing problems and frailty; we must consider that in our sample the prevalence of overweight and obesity was $75 \%$, which could dissipate the effect of tooth loss on frailty among the elderly in Coyoacán. On the other hand, elderly people living in Mexico who have few (1-9) teeth and who wear nonfunctional dental prostheses tend to modify their diets, increasing the consumption of lownutrient foods. This could explain the fact that many of them are overweight and obese, and it could hide the effects of having few or no teeth on the risk of frailty and mortality [34,35]. It is important to mention that obese sarcopenia could be a confounding factor in the evaluation of frailty [54].

Several researchers have measured dental variables with physical activity. Takata and cols., explored the association between chewing ability and number of teeth with physical activity using hand grip strength, leg extensor strength, leg extensor power, stepping rate, and one-leg standing time as indicators. These are specific measurements of physical activity, one of the components of frailty. However, comparisons with our study are difficult because we used The Physical Activity Scale for the Elderly (PASE) [38], an instrument designed for screening for low physical activity in the elderly. Also, we measured frailty as a whole and not considering the components individually. Even when the associations of chewing ability and number of teeth with frailty were statistically significant in the univariate model, in the logistic regression model the associations disappeared. Similarly, Takata did not find association with number of teeth; but when comparing the number of chewable foods they observed an increase in isokinetic leg extension power and in one-leg standing time, association that we did not observed with frailty. The type of measurement for physical activity used in this study might be a limitation, it is worth considering in future studies a more detailed measurement [55].
It is important to mention that this study included clinical evaluation of dental variables as well as questions about self-perception of oral health and self-reports of utilization of dental services during the last year. None of these variables has been considered in other reports on frailty. However, the inclusion of several oral health conditions represents a challenge because of the mutually exclusive characteristics of some dental variables (e. g., periodontitis and edentulism).

We recognize the need for a global oral health indicator, and we question, "What would be an optimal oral health indicator in the elderly, and how can we measure it?" A global oral health indicator should be able to classify those people who are properly rehabilitated (using functional dental prosthesis) and have no periodontal problems. It should also be able to classify those with complex oral conditions (e.g., nonfunctional dental prosthesis and periodontal disease in the remaining teeth, or presence of remaining roots), which could increase the risk of developing other chronic conditions, favoring energy imbalance and creating clinical and therapeutic challenges.

The covariates measured in this analysis were consistent with those measured in previous reports; we observed a higher risk of frailty among those who had been hospitalized during the previous year, those who consumed higher number of drugs on a daily basis, those who reported incontinence, and those who had a history of myocardial infarction [26,27,51,56-58].

\section{Study limitations}

Due to the cross-sectional nature of the study design, causal inferences cannot be made. In order to deepening in the relationship between oral health status and frailty, it is necessary to perform longitudinal studies.

Even though the non-response rate was $25 \%$ for the dental clinical evaluation, many characteristics of those who accepted and those who did not accept the oral clinical evaluation were similar. Similarities between responding and non-responding groups were found with respect to sociodemographic characteristics such as age and gender, medical variables, dental services utilization, and self-perception of oral health. The number of years of education completed was higher among those who did not accept the oral clinical evaluation. As a whole, these results imply that there are no differences between subjects who were clinically evaluated and those who were not. Certain oral health-related variables, such as coronal and root caries and oral mucosal lesions, were not evaluated because of time constraints on the clinical evaluations. Furthermore, it is possible that the mutually exclusive relationships between some clinical dental data (e.g., periodontitis and edentulism) interfere with the inclusion of the variables in the analysis. Another 
limitation could be the type of measurements used for frailty; we used epidemiological screening methods recommended for the elderly population. In order to have more accurate results it can be considered the utilization of more detailed measurements for the components of frailty in future studies.

\section{Conclusions}

Low utilization of dental services and poor selfperception of oral health could be considered possible risk markers for frailty syndrome. The role of periodontitis and other oral clinical variables in frailty should be explored in longitudinal studies. The comprehensive geriatric assessment should include a question about self-perception of oral health, because this question reflects both objective and subjective aspects of health and is associated with a higher probability of being frail. The inclusion of a question about utilization of dental services during the previous year on the comprehensive geriatric assessment should also be considered, because the answer to this question is related to other factors that can promote the development of frailty.

\section{Abbreviations}

CD: Complete Denture; INCMNSZ: Instituto Nacional de Ciencias Médicas y Nutrición "Salvador Zubirán" (Institute of Medical Sciences and Nutrition "Salvador Zubirán"); INSP: Instituto Nacional de Salud Pública (National Institute of Public Health); MMSE: Mini-Mental State Examination; PSR: Periodontal Screening and Recording Index; RPD: Removable Partial Denture; SD: Standard Deviation; UNAM: Universidad Nacional Autónoma de México (National Autonomous University of Mexico); WHO: World Health Organization.

\section{Competing interests}

The authors declare that they have no competing interests.

\section{Authors' contributions}

SABY, LMGR, and JAAF participated in the design of the study. RCCP and SABY performed data analysis, interpreted the data and drafted the manuscript. All authors read and approved the final manuscript.

\section{Acknowledgements}

The Mexican Study of Nutritional and Psychosocial Markers of Frailty among Community-Dwelling Elderly was funded by the National Council for Science and Technology of Mexico (SALUD-2006-C01-45075), and the Dental School at the National Autonomous University of Mexico.

\footnotetext{
Author details

${ }^{1}$ Programa de Maestría y Doctorado en Ciencias Médicas, Odontológicas y de la Salud, Universidad Nacional Autónoma de México, Ciudad Universitaria, Av. Universidad 3000, Del. Coyoacán C.P. 04510Distrito Federal, México. ${ }^{2}$ Coordinación de Salud Pública Bucal, División de Estudios de Posgrado e Investigación, Facultad de Odontología, Universidad Nacional Autónoma de México, Ciudad Universitaria, Av. Universidad 3000, Del. Coyoacán, C.P. 04510Distrito Federal, México. ${ }^{3}$ Instituto Nacional de Geriatría, Blvd. Adolfo Ruíz Cortines 2767, Col. San Jerónimo Lídice, Del. Magdalena Contreras C.P. 10200Distrito Federal, México. ${ }^{4}$ Clínica de Geriatría, Instituto Nacional de Ciencias Médicas y Nutrición,"Salvador Zubirán”, Vasco de Quiroga 15, Col. Sección XVI, Del. Tlalpan C.P. 14000Distrito Federal, México.
}

Received: 5 April 2012 Accepted: 3 September 2012

Published: 12 September 2012

\section{References}

1. Petersen PE: The World Oral Health Report 2003. In Edited by Programme WGOH. Geneva: World Health Organization; 2003:45.

2. Sheiham A: Oral health, general health and quality of life. Bull World Health Organ 2005, 83(9):644.

3. Locker D: Concepts of oral health, disease and the quality of life. In Measuring oral health and quality of life. Edited by Slade G 1997:11-24.

4. Hummel SK, Wilson MA, Marker VA, Nunn ME: Quality of removable partial dentures worn by the adult U.S. population. J Prosthet Dent 2002, 88(1):37-43.

5. Petersen PE, Kandelman D, Arpin S, Ogawa H: Global oral health of older people-call for public health action. Community Dent Health 2010, 27(4 Suppl 2):257-267.

6. Petersen PE, Ueda H, Oral Health in Ageing Societies: Integration of oral health and general health report of a meeting convened at the WHO, Centre for Health Development in Kobe, Japan 1-3 June 2005. Geneva: World Health Organization; 2006:59.

7. Petersen PE, Yamamoto T: Improving the oral health of older people: the approach of the WHO Global Oral Health Programme. Community Dent Oral Epidemiol 2005, 33(2):81-92.

8. Polzer I, Schimmel M, Muller F, Biffar R: Edentulism as part of the general health problems of elderly adults. Int Dent J 2010, 60(3):143-155.

9. Brennan DS, Spencer AJ, Roberts-Thomson KF: Tooth loss, chewing ability and quality of life. Qual Life Res 2007, 17(2):227-235.

10. Jung YM, Shin DS: Oral health, nutrition, and oral health-related quality of life among Korean older adults. J Gerontol Nurs 2008, 34(10):28-35.

11. Lahti S, Suominen-Taipale L, Hausen $\mathrm{H}$ : Oral health impacts among adults in Finland: competing effects of age, number of teeth, and removable dentures. Eur J Oral Sci 2008, 116(3):260-266.

12. N'Gom PI, Woda A: Influence of impaired mastication on nutrition. J Prosthet Dent 2002, 87(6):667-673.

13. Nowjack-Raymer RE, Sheiham A: Numbers of natural teeth, diet, and nutritional status in US adults. J Dent Res 2007, 86(12):1171-1175.

14. Sahyoun NR, Lin CL, Krall E: Nutritional status of the older adult is associated with dentition status. J Am Diet Assoc 2003, 103(1):61-66.

15. Walls A, Steele J: The relationship between oral health and nutrition in older people. Mech Ageing Dev 2004, 125(12):853-857.

16. Walls AW, Steele JG, Sheiham A, Marcenes W, Moynihan PJ: Oral health and nutrition in older people. J Public Health Dent 2000, 60(4):304-307.

17. Koehler J, Leonhaeuser I-U: Changes in food preferences during aging. Ann Nutr Metab 2008, 52(1):15-19.

18. Parker B, Chapman I: Food intake and ageing? The role of the gut. Mech Ageing Dev 2004, 125(12):859-866.

19. Mealey BL, Ocampo GL: Diabetes mellitus and periodontal disease. Periodontol 2007, 44:127-153

20. Karnoutsos K, Papastergiou P, Stefanidis S, Vakaloudi A: Periodontitis as a risk factor for cardiovascular disease: the role of anti-phosphorylcholine and anti-cardiolipin antibodies. Hippokratia 2008, 12(3):144-149.

21. Syrjala AM, Ylostalo P, Hartikainen S, Sulkava R, Knuuttila M: Number of teeth and selected cardiovascular risk factors among elderly people. Gerodontology 2010, 27(3):189-192.

22. Touger-Decker R: Diet, cardiovascular disease and oral health: promoting health and reducing risk. J Am Dent Assoc 2010, 141(2):167-170.

23. Felton DA: Edentulism and comorbid factors. J Prosthodont 2009 18(2):88-96

24. Petersen PE: The World Oral Health Report 2003: continuous improvement of oral health in the 21st century-the approach of the WHO Global Oral Health Programme. Community Dent Oral Epidemiol 2003, 31(Suppl 1):3-23.

25. Sheiham A, Watt RG: The common risk factor approach: a rational basis for promoting oral health. Community Dent Oral Epidemiol 2000, 28(6):399-406

26. Fried $L P$, Tangen $C M$, Waltson J: Frailty in older adults: evidence for a phenotype. J Gerontol 2002, 56(A):M146-M156.

27. Fried LP, Ferrucci L, Darer J, Williamson JD, Anderson G: Untangling the concepts of disability, frailty, and comorbidity: implications for improved targeting and care. J Gerontol A Biol Sci Med Sci 2004, 59(3):255-263.

28. Lipsitz LA: Physiological complexity, aging, and the path to frailty. Sci Aging Knowledge Environ 2004, 2004(16):pe16-pe16.

29. Walston J: Frailty-the search For underlying causes. Sci Aging Knowledge Environ 2004, 2004(4):4pe-4 
30. Ahmed N, Mandel R, Fain M: Frailty: an emerging geriatric syndrome. Am J Med 2007, 120(9):748-753.

31. Powell C: Frailty: help or hindrance? J R Soc Med 1997, 90(Suppl 32):23-26.

32. Avila-Funes JA, Pina-Escudero SD, Aguilar-Navarro S, Gutierrez-Robledo LM, Ruiz-Arregui L, Amieva H: Cognitive impairment and low physical activity are the components of frailty more strongly associated with disability. J Nutr Health Aging 2011, 15(8):683-689.

33. Topinkova E: Aging, disability and frailty. Ann Nutr Metab 2008 52(Suppl 1):6-11.

34. Avlund K, Schultz-Larsen K, Christiansen N, Holm-Pedersen P: Number of teeth and fatigue in older adults. J Am Geriatr Soc 2011, 59(8):1459-1464.

35. Semba RD, Blaum CS, Bartali B, Xue QL, Ricks MO, Guralnik JM, Fried LP: Denture use, malnutrition, frailty, and mortality among older women living in the community. J Nutr Health Aging 2006, 10(2):161-167.

36. Alvarado BE, Zunzunegui MV, Beland F, Bamvita JM: Life course social and health conditions linked to frailty in Latin American older men and women. J Gerontol A Biol Sci Med Sci 2008, 63(12):1399-1406.

37. Radloff S: The CES-D scale: a self-report depresion scale for research in the general population. App Psychol Meas 1977, 1(3):385-401.

38. Washburn RA, McAuley E, Katula J, Mihalko SL, Boileau RA: The physical activity scale for the elderly (PASE): evidence for validity. J Clin Epidemiol 1999, 52(7):643-651.

39. The Academy of Prosthodontics: The glossary of prosthodontic terms. J Prosthet Dent 2005, 94(1):10-92.

40. Ettinger $\mathrm{RL}$, Jakobsen JR: A comparison of patient satisfaction and dentist evaluation of overdenture therapy. Community Dent Oral Epidemiol 1997, 25(3):223-227

41. Periodontal Screening and Recording; http://www.ada.org/3070.aspx

42. Ostrosky-Solis F, Lopez-Arango G, Ardila A: Sensitivity and specificity of the Mini-mental state examination in a Spanish-speaking population. Appl Neuropsychol 2000, 7(1):25-31.

43. Manski RJ, Moeller J, Chen H, St Clair PA, Schimmel J, Magder L, Pepper JV: Dental care utilization and retirement. J Public Health Dent 2010, 70(1):67-75.

44. Wong R, Espinoza M, Palloni A: Adultos mayores mexicanos en contexto socioeconómico amplio: salud y envejecimiento. Salud Publica Mex 2007 49(Suppl 4):S436-S447

45. Kiyak HA, Reichmuth M: Barriers to and enablers of older adults' use of dental services. J Dent Educ 2005, 69(9):975-986.

46. Xue QL, Fried LP, Glass TA, Laffan A, Chaves PHM: Life-space constriction, development of frailty, and the competing risk of mortality: The Women's Health and Aging Study I. Am J Epidemiol 2007, 167(2):240-248.

47. Mezuk B, Edwards L, Lohman M, Choi M, Lapane K: Depression and frailty in later life: a synthetic review. Int J Geriatr Psychiatry 2011, 27(9):879-892

48. Ni Mhaolain AM, Fan CW, Romero-Ortuno R, Cogan L, Cunningham C, Kenny RA, Lawlor B: Frailty, depression, and anxiety in later life. Int Psychogeriatr 2012, 24(8):1265-1274.

49. Esmeriz CEC, Meneghim MC, Ambrosano G: Self-perception of oral health in non-institutionalised elderly of Piracicaba city, Brazil. Gerodontology 2011, 29(2):e281-e289.

50. Okoro CA, Strine TW, Eke PI, Dhingra SS, Balluz LS: The association between depression and anxiety and use of oral health services and tooth loss. Community Dent Oral Epidemiol 2011.

51. Rockwood K, Fox RA, Stolee P, Robertson D, Beattie L: Frailty in elderly people-an evolving concept. Can Med Assoc J 1994, 150(4):489-495.

52. Fedarko NS: The biology of aging and frailty. Clin Geriatr Med 2011, 27(1):27-37.

53. Walston J, McBurnie MA, Newman A, Tracy RP, Kop WJ, Hirsch CH, Gottdiener J, Fried LP, Cardiovascular Health Study: Frailty and activation of the inflammation and coagulation systems with and without clinical comorbidities. Arch Intern Med 2002, 162(20):2333-2341.

54. Jarosz PA, Bellar A: Sarcopenic obesity: an emerging cause of frailty in older adults. Geriatr Nurs 2009, 30(1):64-70.

55. Takata Y, Ansai T, Awano S, Hamasaki T, Yoshitake Y, Kimura Y, Sonoki K, Wakisaka M, Fukuhara M, Takehara T: Relationship of physical fitness to chewing in an 80-year-old population. Oral Dis 2004, 10:44-49.

56. Gill TM, Gahbauer EA, Allore HG, Han L: Transitions between frailty states among community-living older persons. Arch Intern Med 2006, 166(4):418-423.
57. Mitnitski AB, Graham JE, Mogilner AJ, Rockwood K: Frailty, fitness and latelife mortality in relation to chronological and biological age. BMC Geriatr 2002, 2:1.

58. Morley JE, Perry HM 3rd, Miller DK: Editorial: something about frailty. J Gerontol A Biol Sci Med Sci 2002, 57(11):M698-M704.

doi:10.1186/1471-2458-12-773

Cite this article as: Castrejón-Pérez et al.: Oral health conditions and frailty in Mexican community-dwelling elderly: a cross sectional analysis. BMC Public Health 2012 12:773.

\section{Submit your next manuscript to BioMed Central and take full advantage of:}

- Convenient online submission

- Thorough peer review

- No space constraints or color figure charges

- Immediate publication on acceptance

- Inclusion in PubMed, CAS, Scopus and Google Scholar

- Research which is freely available for redistribution

Submit your manuscript at www.biomedcentral.com/submit
C Biomed Central 